\title{
Prevenção primária: análise de um movimento e possibilidades para o Brasil ${ }^{1}$
}

\author{
Fernando Lacerda Júnior \\ Raquel Souza Lobo Guzzo \\ Pontifícia Universidade Católica de Campinas
}

\begin{abstract}
RESUMO
Este trabalho tem como objetivos refletir sobre a temática da prevenção primária e discutir criticamente sobre algumas das idéias que permeiam este campo. A primeira parte apresenta o surgimento da temática da prevenção em um movimento específico na psicologia dos EUA que critica modelos individualistas e remediativos de atuação. São apresentados aspectos históricos e constitutivos da prevenção primária, a diferenciação entre níveis, tipos e abordagens de prevenção e reflete-se sobre a relação entre prevenção primária e promoção de saúde. Define-se o que são fatores de risco e fatores de proteção e os indicadores e as dimensões do bem-estar. A segunda parte discute problemas e questões controversas no debate sobre a prevenção primária, a partir de noções presentes nos trabalhos de George W. Albee e Emory L. Cowen. Na terceira parte são apresentadas as possibilidades oferecidas por este modelo para a realidade brasileira a partir da crítica a algumas das idéias destacadas. A noção de educação emancipadora e a tomada de uma perspectiva histórica na compreensão da constituição do homem são consideradas como necessárias para a superação do positivismo que permeia noções e práticas preventivas. Enfatiza-se a inseparabilidade entre prevenção e mudança social.
\end{abstract}

Palavras-chave: prevenção primária; história da prevenção; mudança social.

\begin{abstract}
Primary prevention: a movement analysis and possibilities to Brazil

This paper discusses the primary prevention and some ideas developed in this field. The first section presents the origins of prevention theme at a specific movement in US psychology which criticizes the individualistic and remediative frameworks. Historical and constitutive dimensions of primary prevention, differences between preventive levels, types, and approaches and considerations about the relationship between prevention and health promotion are presented. The authors define risk and protection factors, wellness indicators and dimensions. The second section discusses controversies related to primary prevention, based on the ideas presented by G. W. Albee and E. L. Cowen's works. The third section presents critical considerations about this framework at Brazilian social reality. It is argued that the shift from positivism inside preventive ideas and practices have as a necessary condition the notion of emancipatory education and an historical perspective to the comprehension of human development. The inseparability of prevention and social change are emphasized.
\end{abstract}

Keywords: primary prevention; history of prevention; social change.

\section{APRESENTAÇÃO}

Ao longo de 42 anos de regulamentação no Brasil, a psicologia sustentou uma prática hegemonicamente descontextualizada e distante das necessidades da maioria da população brasileira. Tal distanciamento buscava intencionalmente uma suposta neutralidade profissional e científica em relação às questões sociais.
A sociedade injusta e desigual passava a ser legitimada por uma prática profissional voltada para as elites.

Na medida em que o profissional se depara com questões psicossociais e de saúde pública, a prevenção começa a ganhar espaço na busca de aportes para sustentar programas e propostas de formação nesta área.

Este trabalho apresenta reflexões sobre o desenvolvimento da prevenção primária (PP) na psicologia, 
enquanto modelo de intervenção alternativa desenvolvido por um movimento de psicólogos dos EUA preocupados em dar respostas aos problemas sociais daquele país e busca, também, discutir as possibilidades de pensar este modelo de intervenção na realidade brasileira. Deve-se notar que a referência à PP, neste trabalho, restringe-se a um movimento específico apesar de a idéia de prevenção em psicologia não se restringir a tal movimento.

A abordagem ao tema divide-se em três partes. A primeira apresenta a PP na psicologia tendo em vista, principalmente, as origens da mesma e os trabalhos de dois expoentes do campo: George W. Albee e Emory L. Cowen. Esta parte será intercalada com reflexões sobre alguns aspectos comuns existentes entre os questionamentos que levaram à $\mathrm{PP}$ e o desenvolvimento histórico da psicologia no Brasil. A segunda parte discute sobre as concepções de indivíduo e questões controversas presentes no trabalho dos autores citados. A terceira parte tece considerações sobre contribuições da PP e perspectivas para o Brasil.

\section{INTRODUÇÃO}

Ao longo da história, psicólogos buscaram tratar dos problemas (ou desajustamentos, doenças, distúrbios etc.) por meio de atendimentos clínicos, individuais e remediativos, resultantes de uma formação que prioriza este papel, mantendo a profissão associada à doença e ao modelo médico como forma de intervenção. Isto se deu, tanto nos EUA, quanto no Brasil (Albee, 2000; 2003; Guzzo, 2002; 2003).

A intervenção hegemônica na psicologia, de caráter clínico, individualista e remediativo, é voltada, principalmente, para a menor parcela da população brasileira. Pode-se dizer que a Psicologia, predominantemente, tem sido uma ciência e uma profissão desenvolvida por elites para elites. Tal problema não reside apenas no fato da psicologia atender à parcela minoritária da população, mas também, em reproduzir um corpo de conhecimento e intervir de maneira a manter o status quo - na medida em que as idéias centrais da psicologia surgiram para responder às necessidades de grupos dominantes de sociedades que pouco poderiam contribuir para a resolução de problemas das maiorias populares da América Latina (Martín-Baró, 2002).

Trata-se de entender que tal intervenção é resultante de questões de caráter epistemológico, ético, político e, sobretudo, histórico, em que estão imersas a produção científica e a formação profissional na área. Refere-se a um modelo de trabalho que surge em uma circunstância específica e atende a demandas concretas, em uma sociedade marcada pela dominação de uma determinada classe social.

A principal conseqüência das tentativas de ajudar indivíduos, por meio deste modelo é a sustentação e reprodução da ordem social vigente (Albee, 1981; Martín-Baró, 2002; Prillelltensky, 1994). Nesta forma de trabalho estão as profundas marcas do modelo da deficiência (deffect model) e da culpabilização da vítima, ou seja, a noção de que as causas de desordens psicológicas, psicopatologias e distúrbios são internas ao indivíduo e, conseqüentemente, a possibilidade de tratamento é aquela em que se isola e descontextualiza o indivíduo. A psicoterapia foi um dos principais espaços de expressão destas concepções, embora não o único (Albee, 1981). Tal como já foi apontado no passado: "Entre as ciências que na era do capital participaram do ilusionismo que escondeu as desigualdades sociais, historicamente determinadas, sob o véu de supostas desigualdades pessoais biologicamente determinadas, a psicologia certamente ocupou posição de destaque" (Patto, 1991, p. 36).

Uma intervenção focada nas deficiências individuais de forma descontextualizada ignora dimensões culturais, históricas e sociais da constituição do indivíduo. Isto torna a mudança social desnecessária, já que, supostamente, os problemas poderiam ser resolvidos por meio de intervenções que o tomam de forma dicotomizada da realidade (Albee, 1981; 1982; MartínBaró, 2002; Patto, 1991; Prilleltensky, 1994; Sloan, 2002).

Apenas para ilustrar o longo alcance do modelo da deficiência, pode-se citar o quanto psicólogos tentaram minimizar os efeitos de um sistema educacional problemático ou de práticas opressoras dentro da escola, pela intervenção remediativa e individual, que entendia os problemas de aprendizagem como inerentes às próprias crianças. No Brasil, esta prática foi mediada pela simples transplantação do modelo médico para dentro das escolas (Antunes, 2001; Guzzo, 2001; Patto, 1991).

A partir da década de 50 nos EUA surgiram críticas aos modelos remediativos e, assim, buscas por alternativas que pudessem responder aos desafios não resolvidos no campo da saúde mental (Cowen \& cols., 1996). Esta busca por alternativas não foi exclusividade deste país. Diversas correntes e posturas teóricas no Brasil fizeram questionamentos que tiveram conseqüências importantes para a psicologia brasileira, sobretudo na maneira de compreender a importância de tomar o homem em seu caráter histórico e social.

O campo da PP, tema sobre o qual este trabalho se propõe a discutir, emerge de um profundo questiona- 
mento sobre o modelo da deficiência e práticas remediativas e individualistas da psicologia.

\section{Prevenção primária: história e conceitos}

O estudo sobre a PP visa procurar contribuições para o contexto brasileiro de um campo que teve grande impacto não somente nos EUA, mas em diferentes países do mundo. Como exemplos, podem-se citar os livros editados por Albee, Bond e Monsey (1992) e por Prilletensky, Peirson e Nelson (2001) no Canadá que apresentam trabalhos desenvolvidos na América do Norte, na África, na Europa e na Ásia.

Muitas vezes as pré-concepções construídas em relação ao conceito de prevenção são baseadas em reducionismos (tais como considerar prevenção uma mera evitação de doenças) e, por isso, torna-se importante apresentar um debate em torno deste conceito.

\section{A opção pela prevenção primária}

Tal como foi apresentado, a PP na psicologia surge diante de grande insatisfação com a maneira de tratar os problemas individuais. Cowen e cols. (1996) apontam que a psicoterapia foi uma das modalidades de intervenção na área da saúde mental questionada por seu cunho individualista e, também, pela constatação, a partir de estudos epidemiológicos, de que o que pode ajudar indivíduos não, necessariamente, traz contribuições em longo prazo para a sociedade.

Um fator histórico que contribuiu para o desenvolvimento de uma ação clínica e remediativa nos EUA foi, segundo Albee (2000; 2003), a resposta dada pelos departamentos de psicologia das universidades norte-americanas à demanda surgida após a II Guerra Mundial. Ao colocarem seus estudantes dentro de cenários, cuja ideologia advinha da psiquiatria, a formação em psicologia incorporou, de maneira acrítica, visões psiquiátricas de mundo que, nas palavras do autor, eram inválidas ou até mesmo duvidosas. Com isto muitos psicólogos aprenderam a tratar pacientes em consultórios privados. Note-se que a psicologia brasileira também se constituiu enquanto fazer de cunho liberal, clínico e remediativo (cf. Antunes, 2001; Bastos, 2002; Patto, 1991).

As concepções que consideram as desordens psicológicas como internas ao indivíduo, passam a ser postas em cheque, na medida em que se torna visível na psicologia o papel que micro-sistemas, instituições sociais, esperança e justiça desempenham na vida de uma pessoa (Cowen, 1986; 2000b; Cowen \& cols, 1996). Estes questionamentos são elaborados em um período de grandes mudanças na sociedade norte- americana, quando pesquisadores e profissionais passam a atentar para as consequiências emocionais decorrentes de desigualdades sociais - alvo de grande preocupação nos anos 60 e 70 (Albee, 1996; 2003).

Uma das principais críticas elaboradas neste período é expressa por Heller (1996) ao apresentar o tratamento remediativo de indivíduos nos EUA que, por ter altos custos e não reduzir a incidência de doenças (sejam elas físicas ou mentais), não traz contribuições sociais.

Assim, a PP surge no campo da saúde mental como uma intervenção que não visa apenas atingir a maior parte da população, mas transformar a realidade de uma sociedade que produz o sofrimento humano.

A idéia de prevenção baseia-se na tomada de uma posição humanista em relação ao mundo, rompendo o ciclo vicioso que gera problemas sociais, emocionais, cognitivos e comportamentais e é sustentado com os investimentos em serviços de remediação nas áreas de educação, segurança, saúde e etc. (Albee, 1981; 1986; Prilleltensky, Peirson \& Nelson, 2001).

\section{História da prevenção primária}

O conceito PP é proveniente da saúde pública e refere-se à ação que busca evitar a incidência de doenças. As ações neste campo sempre têm como alvo grupos e não indivíduos. No entanto, quando a PP passa a tratar de questões emocionais e mentais tornase algo complexo e denso para ser discutido.

Albee e Joffe (1980) têm como marco para a PP nos EUA, a fundação de Centros Compreensivos Comunitários de Saúde Mental que, por assumirem a concepção de que desordens mentais não são algo natural, mas sim, fenômenos sociais que podem ser evitados, surgem como uma revolução no campo da saúde mental.

As idéias de Albee e Joffe (1980) foram apresentadas na I Conferência sobre PP de Psicopatologia realizada em Vermont em 1975 - a primeira de uma série de conferências fundamentais para o desenvolvimento da PP (Cowen, 1986; Heffernan \& Albee, 1985).

Além das conferências de Vermont, foi de grande importância a elaboração de um relatório federal, em 1978, cujo objetivo era o de apresentar a importância da PP ao governo norte-americano. Este relatório foi alvo de diversos comentários e críticas advindos, principalmente, de psiquiatras - gerando polêmicas em torno da questão da PP em que, por diversas vezes, a psiquiatria apresentou-se como um campo resistente (Albee, 1981; 1982; 1986; 1988; 1996; Goldston, 1988; Lamb, 1988; Zusman, 1988). 
Albee (2000) aponta para o fato de que as diferenças sobre a explicação de doenças entre os modelos médicos, biologicistas e os modelos que buscam causas sociais, são acompanhadas por diferenças na agenda política. Enquanto os primeiros são constituídos ou apoiados por grupos dominantes que não desejam a mudança social, os últimos são constituídos ou apoiados por aqueles que propõem a mudança social como alternativa.

Para Albee $(1981 ; 1982 ; 1986)$ as resistências à prevenção ligadas às diferenças políticas relacionamse principalmente a: (1) uma ideologia calvinista e puritana que coloca o indivíduo como ser predestinado, cujo destino é tomado como imutável; (2) concepções em que a psicopatologia é de ordem genética e, assim, não é possível preveni-la; (3) existência de algum tipo de compromisso (que usualmente é de caráter econômico) por parte dos grupos que defendem o tratamento por meio de terapia individual ou administração de drogas; (4) e, por fim, é mais fácil para famílias ou instituições sociais culpar a vítima ou biologizar o problema do que se enxergar como parte deste.

Dentre os argumentos utilizados contra a PP emergem duas afirmações: a que apresenta os prevencionistas como pessoas que, não conhecendo as verdadeiras causas de psicopatologias, não podem comprovar que o fortalecimento de indivíduos como medida de prevenção às doenças mentais e outra que considera que pessoas que trabalham com questões sociais escapam ao campo da saúde mental (Lamb, 1988; Zusman, 1988). Estes argumentos, ao reforçarem o modelo da deficiência, mascaram forças sociais e, desta forma, contrapõem-se à mudança social. Deve-se notar que a preocupação com a mudança social no movimento da PP visa um processo permanente que demanda ações políticas, definição de valores, relações entre meios e fins, mudanças econômicas etc. (Albee, 1981; 1982; 1996; Hilliard, 1981; Konopka, 1981; Prilleltensky, 1994; Prilleltensky, Peirson \& Nelson, 2001).

Em síntese, a busca pela prevenção vem de preocupações com as consequiências das condições sociais de desigualdade. Estas preocupações nos EUA ganham força nos anos 60 e 70 e levam ao desenvolvimento de atividades preventivas que focam a educação e a mudança social. Por fim, apesar de dificuldades e resistências, o campo da PP desenvolveu-se notavelmente nos EUA, com pesquisas e publicações específicas.

\section{0 conceito de prevenção primária}

O desenvolvimento teórico e prático da PP deu-se de forma fragmentada e heterogênea, culminando em divergências conceituais, utilização de diferentes estratégias e mesmo confusões dentro do campo (Cowen, 1986; 2000a; 2000b).

Além disso, surgiram dificuldades diante de problemas em demonstrar que uma intervenção preventiva impede o surgimento de consequiências negativas para o desenvolvimento humano (Durlak \& Wells, 1997).

Houve um período de grande produção sobre a PP em que a maioria dos trabalhos visava demonstrar que a PP funcionava e era possível, enquanto outros discutiam diferentes estratégias para a mesma. Este foi um momento importante para a consolidação de um campo emergente (Albee \& Joffe, 1980; Durlak \& Wells, 1997). Parte desta produção conduziu ao desenvolvimento de intervenções que enfatizam a promoção do bem-estar (wellness) como um processo de mudanças sociais que demandam por estratégias preventivas (Prilleltensky, Peirson \& Nelson, 2001).

A prevenção, enquanto modelo de trabalho, originou-se na saúde pública e foi organizada em três níveis (Goldston, 1980):

- Prevenção Primária - ações dirigidas a grupos amplos, tomadas antes de uma doença se estabelecer e possuem um caráter educativo maior do que os outros níveis.

- Prevenção secundária - ocorre após a identificação de fatores de risco e busca evitar que o problema se torne crônico, por meio de diagnóstico e intervenção precoces.

- Prevenção terciária - o mais específico de todos os níveis e busca reabilitar ou minimizar os efeitos de uma doença já instalada.

Deve-se notar que esta diferenciação é parecida com a diferenciação feita pelo Instituto de Medicina dos EUA para intervenções na saúde mental (Muñoz, Mzarek \& Haggerty, 1996), em que são introduzidos os seguintes conceitos:

- Prevenção - intervenção antes do início de uma desordem psicológica;

- Tratamento (treatment) - identificação de casos e disponibilização de serviços de saúde mental;

- Manutenção (maintenance) - ações que buscam minimizar danos e oferecer serviços de reabilitação, após a desordem se instalar.

Para Durlak e Wells (1997) a PP é uma "intervenção intencionalmente designada a reduzir a futura incidência de problemas de ajustamento em populações normais, assim como a promoção do funcionamento mental saudável" (p. 117). 
No entanto, a própria definição do conceito PP gerou algumas confusões. Por exemplo, Goldston (1980), preferindo evitar confusões semânticas, apresenta prevenção como sinônimo de PP e, desta forma, poder-se-ia deixar de confundir tratamento e manutenção com prevenção. Cowen (2000a), apresenta diferenciações entre prevenção, prevenção na saúde mental, PP e PP na saúde mental. Sendo que o primeiro é o mais amplo, pois inclui os três níveis de prevenção e envolve um grande número de profissionais. O último, o mais específico, busca prevenir conseqüências adversas à saúde mental e refere-se a um grupo específico de profissionais.

Durlak e Wells (1997), na tentativa de diminuir confusões conceituais, elaboraram uma síntese a partir de uma meta-análise de relatórios e produções no campo da prevenção. Os autores apresentam seis abordagens possíveis em PP considerando duas grandes dimensões que se articulam entre si. A primeira dimensão refere-se às estratégias escolhidas por programas de PP (Durlak \& Wells, 1997):

- Programas centrados no ambiente/sistema - enfatizam a prevenção de problemas específicos ou a promoção do bem-estar. A estratégia consiste em mudar o ambiente para se atingir objetivos definidos pelo programa de intervenção. Muitas abordagens que adotam esta estratégia entendem que injustiças sociais e falta de oportunidades estão relacionadas aos problemas psicológicos e, desta forma, orientam-se para mudanças políticas e sociais.

- Programas centrados na pessoa - também podem enfatizar a prevenção de problemas específicos ou a promoção de bem-estar. Os programas visam atingir diretamente uma populaçãoalvo. As intervenções podem ser reativas tentando evitar desajustamentos que surgem em situações específicas ou podem ser proativas promovendo o desenvolvimento do bem-estar.

A segunda dimensão refere-se à maneira como a população é selecionada para a intervenção (Durlak \& Wells, 1997; Muñoz, Mzarek \& Haggerty, 1996):

- Universal - todos os membros de uma população são alvos da intervenção, existem poucos riscos de consequiências negativas e, idealmente, são mais baratas;

- Selecionada - intervenção voltada a indivíduos ou subgrupos em que a probabilidade de incidência de uma desordem específica é maior;

- Indicada - voltada para indivíduos ou subgrupos, que já apresentam sintomas iniciais de uma desordem.
Esta classificação surgiu diante de problemas que decorreram da expansão do campo da PP a qual contemplava, desde atividades que focavam problemas comportamentais e emocionais específicos, até atividades de promoção de saúde e de mudanças políticas e sociais (Durlak \& Wells, 1997).

Em uma perspectiva diferente, Muñoz, Mzarek e Haggerty (1996) separam as atividades de promoção da saúde de atividades preventivas, pois, para os autores, estas focam o bem-estar enquanto aquelas as doenças. Albee (1996) critica tal distinção, por considerá-la decorrente de uma compreensão sobre sofrimento humano, baseada em manuais como o DSM (APA, 1994) que desqualificam qualquer ação de caráter político ou social como, por exemplo, a promoção de saúde.

Cowen (1997), a partir das diferenças entre as concepções de PP, de Durlak e Wells (1997) e de Muñoz, Mzarek e Haggerty (1996), concluiu que existem duas lógicas em PP na saúde mental - independentes da estratégia ou da população escolhidas: uma que busca antecipar-se às desordens mentais por meio da identificação de fatores de risco e outra que visa reforçar e desenvolver o bem-estar. O problema, para o autor, é que a primeira lógica manteve-se dominante sobre a segunda por ter resultados mais visíveis a curto e médio prazo.

A primeira lógica tem alguns passos básicos em uma seqüência mais ou menos fixa:

\section{1) identificar a séria desordem (por exemplo, do tipo DSM-IV) que se espera prevenir; 2) revisar o co- nhecimento sobre fatores de risco e proteção relacio- nados ao início da desordem; 3) desenvolver, con- duzir e avaliar intervenções-piloto fundamentadas no conhecimento estabelecido no passo dois; 4) Am- pliar programas piloto efetivos para tentativas de prevenção em larga escala; e 5) Usar técnicas de disseminação para promover a aplicação de mode- los efetivos no nível comunitário (Cowen, 2000a, p. 8).}

As limitações deste modelo levaram ao desenvolvimento de trabalhos permeados pela lógica de promoção do bem-estar. As diferenças são: enquanto o modelo de identificação de fatores de risco busca prevenir desordens psicológicas por meio de sua neutralização, o segundo busca maximizar o bem-estar por meio da identificação de forças protetoras e condições que o promovem. Este modelo é de caráter universal, complexo e sistêmico e não é guiado somente por estratégias centradas em pessoas, pois busca mudar instituições sociais que impedem a promoção do bemestar (Cowen, 2000a; 2000b). 
Nesta concepção mais abrangente, um aspecto nem sempre explícito, é o caráter, necessariamente, educativo da intervenção preventiva e que, por isso, não se distingue das atividades de promoção de saúde (Goldston, 1980).

\section{Fatores de risco e fatores de proteção}

O estudo da prevenção não é possível sem o estudo dos fatores de risco e dos fatores de proteção. Fatores de risco são as características ou variáveis que, se presentes em um contexto, tornam pessoas ou grupos mais vulneráveis ao desenvolvimento de desordens psicológicas, enquanto que fatores de proteção modificam ou diminuem o efeito dos fatores de risco (Muñoz, Mzarek \& Haggerty, 1996). A existência de fatores de proteção pode ser percebida pelo não-desenvolvimento de problemas psicológicos, porém a presença de fatores de risco não, necessariamente, resulta em desordens psicológicas (Trombeta \& Guzzo, 2002).

Os programas de intervenção preventiva focalizam um ou outro tipo de fator de acordo com as estratégias adotadas. Estratégias que buscam se antecipar às desordens psicológicas priorizam os fatores de risco, enquanto estratégias de promoção do bem-estar priorizam o estudo dos fatores de proteção (Cowen, 2000a).

Tanto o Instituto Nacional de Saúde Mental quanto o Comitê de Prevenção do Instituto de Medicina dos EUA concluíram em seus relatórios, pela priorização de estratégias que visam reduzir fatores de risco (Reiss \& Price, 1996; Muñoz, Mzarek \& Haggerty, 1996).

Para Cowen (1991) a contribuição que a prevenção pode dar para a melhoria da condição humana é maior quando deixa de trabalhar, prioritariamente, em um modelo que enfatiza a doença e assume outro que promove o bem-estar: uma mudança da luta contra a doença para a construção do bem-estar. A promoção do bem-estar implica em intervenções mais complexas e controversas, pois demandam atenção a diversos tópicos tais como: educação, família, instituições sociais, dentre outros (Albee, 1996; Cowen, 1991; 2000a).

Existem dois indicadores básicos de bem-estar: 1) aqueles que se referem às necessidades tais como comer, dormir ou trabalhar bem; e (2) os que se referem às necessidades tais como ter sensação de controle sobre a própria vida, sentido de pertencimento etc. (Cowen, 1991).

Cowen (1991) apresenta cinco tipos de ameaças ao bem-estar e quatro dimensões que podem contribuir para a sua promoção. As ameaças são: (a) necessidades básicas de crianças não atendidas ao longo de seu desenvolvimento; (b) vivências educacionais que produzem a experiência de fracasso pela criança e que falharam em desenvolver competências e habilidades; (c) eventos e circunstâncias que impedem o bemestar; (d) contextos sociais específicos que minam o bem-estar; e (e) fatores macro-sociais tais como injustiça e pobreza.

As dimensões necessárias para a promoção do bem-estar dividem-se entre aquelas que focam características individuais (competência e resiliência) e outras que focam aspectos sociais (fortalecimento e mudança do sistema social):

- Competência - relaciona-se com o que uma pessoa pode ou deve fazer bem. Algumas se relacionam com determinados papéis (mecânica, desenho etc.) e outras são genéricas (relacionamento interpessoal, comunicação etc.).

- Resiliência - a capacidade do indivíduo de crescer sadio, mesmo diante de muitos fatores de risco.

- Modificação do sistema social - instituições sociais podem agir positiva ou negativamente sobre as pessoas e, desta forma, deve haver mudanças naquelas que não permitem o desenvolvimento do bem-estar.

- Fortalecimento (empowerment) - A inexistência de bem-estar relaciona-se com a falta de justiça e igualdade. O fortalecimento relacionase à promoção de políticas e condições que permitam os indivíduos terem controle sobre a própria vida.

\section{Da prevenção primária à psicologia crítica}

Finalizando, pode-se apontar alguns desencadeamentos na psicologia norte-americana que, de uma forma ou de outra, foram influenciados pelas obras de Albee e Cowen e outros autores ligados ao movimento apresentado.

A partir da segunda metade da década de 80 , começa a surgir na psicologia norte-americana, um movimento chamando a atenção para a necessidade de uma crítica à psicologia e à sociedade que se autodenominou, primeiramente, de psicologia radical e, em seguida, psicologia crítica. Expoentes deste movimento fazem referências às idéias de Albee e Cowen, enquanto autores que elaboraram críticas e buscaram alternativas à psicologia hegemônica, mesmo que por caminhos diferentes dos trilhados pelo movimento da psicologia crítica (cf: Fox \& Prilleltensky, 1997; Prilleltensky, 1994; Sloan, 2002). 
Assim, pode-se dizer que o movimento de PP foi um momento importante de elaboração de críticas e de novas ações diante das práticas hegemônicas que, usualmente, eram de cunho individualista e remediativo. Tais elaborações alternativas permitiram a constituição de pontos de ruptura na psicologia norte-americana, apesar de conter idéias que hoje podem ser consideradas superadas. Desta forma, expor estas idéias e problematizar as circunstâncias em que surgiram as necessidades que atendem e a possibilidade de pensá-las no Brasil são objetivos das reflexões a seguir.

\section{Problemas e questões controversas}

Já foi afirmado que a PP surge como um modelo para a ação do psicólogo e, assim, contém, implícita ou explicitamente, concepções de homem e de doença ou desajustamento. Considerando-se que Albee e Cowen foram expoentes na produção sobre PP, tomou-se para análise e crítica as concepções que permeiam suas produções.

\section{Disfunção psicológica}

Emory Cowen possui uma extensa produção que, desde o início, esteve relacionada à questão do acesso à psicoterapia. Assim, seu trabalho desenvolvido no Centro de Estudos Comunitários de Rochester/NY, voltou-se, principalmente, para o desenvolvimento de modelos de intervenção alternativos ao contexto tradicional de trabalho do psicólogo e, especificamente, à $\mathrm{PP}$, ao bem-estar de crianças e a programas de prevenção em escolas (Cowen \& cols, 1996).

Nas publicações consultadas para o presente trabalho não foram encontradas definições explícitas sobre a questão de concepção de indivíduo ou de doença. No entanto, alguns apontamentos podem ser feitos a partir das noções de disfunção psicológica (psychological dysfunction) e de desajustamento (maladjustment).

Cowen e cols. (1996) delineiam estas questões superficialmente. Tal como é apresentada pelos autores, a questão da doença foi tratada de diferentes maneiras nos distintos momentos da história humana sendo que, na medida em que há uma atenção maior ao indivíduo psicológico, há uma crescente atenção às disfunções psicológicas e estas tomam um significado cada vez mais abrangente no âmbito das ações profissionais. Explicações que ligam a questão da doença ao ambiente passam a ocupar mais espaços do que explicações que entendem a doença enquanto fenômeno de ordem biológica e médica. A partir daí surgem compreensões que enfatizam o papel desempenhado por fatores como: microsistemas, justiça e desigualdade (Cowen \& cols, 1996; Cowen, 2000b). Nota-se, assim, que as desordens psicológicas para Cowen podem ser apontadas, a partir de dimensões ambientais que levam ao desajustamento e de forças sociais (tais como injustiça). Além disso, para o autor manuais como o DSMIV (APA, 1994) são necessários e importantes para o conhecimento das desordens psicológicas (Cowen \& cols, 1996).

Como implicação desta concepção, um dos principais programas de prevenção desenvolvido por Cowen - Projeto de Prevenção Primária em Saúde Mental tem o objetivo de "aperfeiçoar a adaptação escolar e a aprendizagem em jovens e crianças que apresentaram sinais de risco para desajustamento e/ou fracasso escolar" (Cowen \& cols, 1996, p.24).

A questão da disfunção psicológica aparece, fundamentalmente, ligada à adaptabilidade da criança ao meio. Assim, as idéias de Cowen apontam para a formulação de programas voltados para competências/situações que estão presentes/ausentes e levam ao ajustamento/desajustamento (Cowen, 1986; Cowen \& cols, 1996).

Nota-se que, mesmo tentando criticar um modelo de intervenção que considerou superado, Cowen não transcendeu a ideologia liberal que permeia a psicologia norte-americana, sobretudo ao fundamentar-se sobre a questão do desajustamento. Provavelmente este tenha sido um fator determinante para as inúmeras replicações de seu programa de prevenção em diversas escolas dos EUA e do mundo.

Assim como outras correntes presentes na psicologia norte-americana, o trabalho de Cowen reproduz ideais democráticos, mas que não superam a psicologia hegemônica com todos os seus problemas e conceitos como o de ajustamento/desajustamento. Este processo é muito bem explicitado na seguinte citação de Patto, a qual se refere às teorias da carência cultural, mas que contempla a questão da ideologia liberal na psicologia:

\begin{abstract}
Aliás, uma psicologia que desde o seu nascimento baseia-se numa definição conservadora de ajustamento e de normalidade e que centra suas investigações no que ocorre no indivíduo ou nas relações interpessoais, entendidos como entidades a-históricas, só poderia ter imensa receptividade numa sociedade regida pelas teses liberais e por uma visão funcionalista da vida social (Patto, 1991, p. 46).
\end{abstract}

Um último aspecto a ser destacado é a ênfase dada pelo autor às potencialidades do indivíduo e à contri- 
buição destas na construção do bem-estar (Cowen, 1991; 2000a; 2000b). Este olhar do autor, em seus últimos trabalhos, vem influenciado pelos trabalhos de Bronfenbrenner sobre a ecologia do desenvolvimento humano. Em um dos últimos artigos do autor há a indicação de ruptura com o conceito de disfunção apontando para a necessidade de se considerar os conceitos de micro-, meso-, exo- e macro-sistema (Cowen, 2000b).

\section{Incidência de psicopatologia}

Albee (1996) define desordem mental como desajustamentos aprendidos socialmente adquiridos ligados às experiências estressoras que resultam em comportamentos desaprovados socialmente. Esta concepção liga-se a duas produções anteriores do autor. A primeira é uma revisão bibliográfica produzida em coautoria com Kessler que é finalizada com a seguinte consideração: "Em cada lugar que olhamos e cada pesquisa examinada sugeriram que as maiores fontes de pressão/tensão [stress] e angústia humana [distress] geralmente envolvem alguma forma de poder excessivo" (Kessler \& Albee, 1980).

A partir desta conclusão, Albee (1981) considera inaceitável procurar deficiências internas ao indivíduo quando existem situações em que há evidências de fontes de opressão. O que, para autor, conduz à necessidade de adotar um modelo de aprendizagem social, posteriormente, expresso na seguinte fórmula (Albee, 1984):

\begin{tabular}{|c|c|}
\hline \multirow{2}{*}{$\begin{array}{l}\text { Incidência de } \\
\text { psicopatologia = }\end{array}$} & $\begin{array}{l}\text { fatores orgânicos + pressão/tensão (stress) } \\
+ \text { exploração }\end{array}$ \\
\hline & $\begin{array}{l}\text { Habilidades de enfrentamento + } \\
\text { auto-estima + suporte }\end{array}$ \\
\hline
\end{tabular}

Esta fórmula aparece com a convicção de que esforços de prevenção, quando separados da ação política e da busca por igualdade social, dissociavamse dos questionamentos que levaram à constituição dos movimentos prevencionistas.

\section{Crítica aos fundamentos de Albee e Cowen}

O colonialismo, a que o Brasil esteve submetido ao longo de toda sua história, reproduziu-se no âmbito científico, trazendo técnicas e modelos individualistas, que simplesmente ignoram ou justificam uma realidade de desigualdades e injustiças. Desta forma, um exame crítico de todas as idéias apresentadas anteriormente é necessário.
Desde a primeira parte do artigo podem-se notar fragilidades e fragmentações no desenvolvimento do campo da PP. Estes problemas decorrem de um modelo de ciência positivista que separa o teórico e o empírico, hipertrofiando o último, e transforma o conhecimento em constatação (González Rey, 1997). A questão da saúde e da doença na prevenção foi trabalhada mais na busca de demonstrar que os programas preventivos funcionavam do que no desenvolvimento e na integração teóricos do sem-número de trabalhos produzidos.

As idéias desenvolvidas por Cowen, se reproduzidas acriticamente, podem levar a sérios problemas. Afinal, o objetivo de adaptar a criança à escola minimizando suas disfunções psicológicas conduz a uma grande contradição: adaptar e ajustar a criança a uma escola que perpetua a opressão, a exploração e a dominação burguesa. Tal como Potts (2003) aponta: em uma realidade de opressão não é a criança que deve ser ajustada à escola.

Outro problema que pode ser destacado é a ligação das desordens/doenças psicológicas a manuais como o DSM. O modelo de doença elaborado nestes manuais vem recebendo duras críticas, principalmente, no que diz respeito à crescente patologização da vida cotidiana (Moreira \& Sloan, 2002) e também sobre a controversa relação entre a crescente listagem de doenças nestes manuais e o pagamento de seguros de saúde especialmente nos EUA onde tal pagamento está condicionado à explicitação oficial de doenças que se dá por meio da publicação nestes manuais. Albee (1986) aponta que a classificação de doenças "verdadeiras" doenças listadas no DSM (APA, 1994) e outros manuais - surge para que terapeutas possam ganhar com as companhias de seguro dos EUA.

No entanto, há uma inovação nas idéias propostas por Cowen: quando estas apontam para o desenvolvimento das potencialidades (resiliência, fortalecimento etc.) do indivíduo. Guzzo (2002; 2003), compartilhando com a mudança de foco proposta por este autor, critica um modelo profissional do psicólogo brasileiro que prioriza o tratamento da doença e, assim, apresenta a possibilidade de um novo horizonte para a profissão.

Deve-se, contudo, perguntar sobre as possíveis contribuições destas dimensões enquanto não forem integradas e entendidas em uma concepção coerente e consistente de homem sem cindi-lo em diversas dimensões que se justificam por si só. Além disso, o olhar para tais dimensões pode recair na individualização das contradições sociais e, assim, resultar em intervenções que, sob novas roupagens, continuam a sustentar o status quo. 
Já nas idéias de Albee há grande atenção para os efeitos perversos de fenômenos tais como exploração, opressão etc. sobre o desenvolvimento humano. Porém, é notável a reprodução do mecanicismo positivista quando a questão da saúde e da doença é reduzida a uma questão de presença ou ausência de variáveis específicas expressas em uma fórmula.

Novamente, as reflexões elaboradas por Potts (2003) sobre a PP são importantes. Para o autor, mesmo enquanto alternativa elaborada na psicologia norte-americana a PP não escapa do positivismo, ahistoricismo e individualismo. Isto, muitas vezes, resulta em ações cujo caráter alternativo aos modelos hegemônicos é questionável.

Se há a pretensão de se trabalhar criticamente com a prevenção na realidade brasileira deve-se, antes de tudo, pensar o que se entende de categorias como indivíduo, saúde e doença em um paradigma que supere os descaminhos, aos quais conduz o positivismo. Para González Rey (1997), a concepção estática e ahistórica da realidade, o atomismo e as falsas dicotomias (indivíduo-sociedade, objetividade-subjetvidade etc.) que existem no positivismo, possuem diversas implicações, das quais aqui são destacadas apenas duas: (1) as pessoas são concebidas como coisas, passivas, separadas da sociedade e (2) há a subestimação de processos comunicativos e dos sistemas relacionais em que as pessoas existem. Pode-se entender que os problemas das intervenções preventivas estão intrinsecamente ligados às concepções de indivíduo e sociedade presentes no positivismo.

\section{Considerações finais: PP no Brasil?}

Por fim, pode-se perguntar: a idéia de prevenção é relevante para o Brasil? Apesar das críticas elaboradas é possível destacar contribuições que devem ser valorizadas. Primeiramente, há a importante tentativa de se sistematizar intervenções guiadas por lógicas diferentes dos modelos de trabalho individualistas e remediativos. Diversas vezes mencionou-se problemas dos modelos que focam o problema/doença no indivíduo e que têm como horizonte a remediação. Mesmo após décadas de críticas provenientes das mais diferentes correntes na psicologia brasileira ou fora dela, tais modelos continuam a marcar a formação, a ciência e a profissão no Brasil. Albee (1981), ao tentar encontrar explicações sobre a razão de certas proposições se manterem apesar de serem criticadas, chegou à seguinte conclusão: "Argumentos fracos expressos por pessoas poderosas possuem uma maneira especial de ganhar a aura e a credibilidade do locutor" (p. 10). Isto quer dizer que certas questões permanecem por razões políticas e derrotá-las demanda muito mais do que apresentar os fundamentos que justifiquem as necessárias mudanças. Enquanto existir a dominação de uma classe específica que explora as demais a hegemonia de uma determinada concepção de homem continuará vigente e, assim, mais do que pensar estratégias de intervenção é preciso pensar os projetos de homem e de sociedade que existem por trás delas.

Potts (2003), ao discutir a questão da PP tendo em vista as necessidades da população afro-americana, tece críticas que convergem às posições aqui defendidas. A partir da meta-análise de Durlak e Wells (1997) o autor destaca que a maior parte dos programas de prevenção em escolas nos EUA são aqueles que adotam estratégias focadas no indivíduo. Os questionamentos e motivações que levaram ao desenvolvimento da PP culminaram em programas que continuam sendo individualistas e baseiam-se no modelo da deficiência.

Em complementação à $\mathrm{PP}$ o autor propõe a educação emancipatória. Assim, um programa de PP necessita sempre situar as questões a serem trabalhadas historicamente sem ignorar dimensões interpessoais, sociopolíticas ou até espirituais. Outra necessidade essencial para os programas de prevenção é a de incorporar a voz da população alvo do programa sobre as manifestações e soluções para o problema que se pretende prevenir, concebendo-os como sujeitos ativos (Potts, 2003). Retoma-se aqui a questão de que a prevenção deve ser entendida como uma intervenção de caráter essencialmente educativo (Goldston, 1980). Tendo em vista essa perspectiva, é interessante tomar algumas idéias de Freire e suas implicações.

A educação para Freire (1973) tem apenas dois objetivos: ou domestica, quando o humano é concebido como objeto passivo, ou liberta, quando o humano é concebido como sujeito ativo. Uma educação emancipadora, para o autor, entende que o ser humano é ativo e reflexivo, capaz de mudar sua realidade, crítico de sua imanência e criativo na transcendência. Tal ser é o que busca a emancipação, alcançando-a, por meio da conscientização - um processo dialético entre objetividade e subjetividade.

Com estes princípios em vista, abrem-se novos horizontes para a PP. Criando-se novas maneiras de intervenção com o homem (ao invés de para o homem) e novas aproximações aos problemas psicossociais e sistemas em que estes existem.

Albee $(1981 ; 1982 ; 1996)$ e outros (cf: Konopka, 1981; Hilliard, 1981) foram capazes de entender que sem a ação política e a mudança social, a intervenção preventiva entra no mesmo beco sem saída que a prática remediativa e individualista. No entanto, faltaram 
concepções que permitissem entender a dinamicidade da história e a complexidade da constituição humana que, reciprocamente, relacionam-se às intervenções de promoção do bem-estar - impossível sem justiça social e sem pessoas capazes de compreender e transformar sua realidade.

\section{REFERÊNCIAS}

Albee, G. W. (1982). Preventing psychopathology and promoting human potential. American Psychologist, 37(9), 1043-1050.

Albee, G. W. (1984). A model for classifying prevention programs. Em J. M. Joffe, G. W. Albee \& L. D. Kelly (Orgs.), Readings in primary prevention of psychopathology ( $\mathrm{pp}$. IXXVIII). Hanover: University Press of New England.

Albee, G. W. (1986). Advocates and adversaries of prevention. Em M. Kessler \& S. E. Goldston (Orgs.), A decade of progress in primary prevention (pp. 309-332). Hanover: University Press.

Albee, G. W. (1988). The argument for primary prevention. Em G. W. Albee, J. M. Joffe \& L. A. Dusenbury (Orgs.), Prevention, powerlessness and politics (pp. 509-515). Newbury Park: Sage Publications.

Albee, G. W. (1996). Revolutions and counterrevolutions in prevention. American Psychologist, 51(11), 1130-1133.

Albee, G. W. (2000). The Boulder model's fatal flaw. American Psychologist, 55(2), 247-248.

Albee, G. W. (2003). Confrontations and change. Em D. K. Freedheim \& I. B. Weiner (Orgs.), Handbook of psychology: History of psychology (pp. 486-488). New Jersey: John Wiley $\&$ Sons.

Albee, G. W. \& Joffe, J. M. (1980). Preface. Em G. W. Albee \& J. M. Joffe (Orgs.), The issues: An overview of primary prevention (pp. XI-XIV). Hanover: University Press.

American Psycchiatric Association (APA). (1994). Diagnostic and statistical manual of mental disorders ( $4^{\mathrm{a}} \mathrm{ed}$.). Washington: APA.

Antunes, M. M. (2001). A psicologia no Brasil: Leitura histórica sobre sua constituição ( $2^{\mathrm{a}}$ ed.). São Paulo: Unimarco.

Bastos, A. V. B. (2002). Perfis de formação e ênfases curriculares. Revista do Departamento de Psicologia da UFF, 14(1), 31-57.

Cowen, E. L. (1986). Primary prevention in mental health: ten years of retrospect and ten years of prospect. Em M. Kessler \& S. E. Goldston (Orgs.), A decade of progress in primary prevention (pp. 3-45). Hanover: University Press.

Cowen, E. L. (1991). In pursuit of wellness. American Psychologist, 44(4), 404-408.

Cowen, E. L. (1997). On the semantics and operations of primary prevention and wellness enhancement. American Journal of Community Psychology, 25(2), 245-255.

Cowen, E. L. (2000a). Now that we all know that prevention in mental health is great, what is it? Journal of Community Psychology, 28(1), 5-16.

Cowen, E. L. (2000b). Prevention, wellness enhancement, Y2K and thereafter. The Journal of Primary Prevention, 21(1), 1519.
Cowen, E. L., Hightower, A. D., Pedro-Carroll, J. L., Work, W. C., Wyman, P. A. \& Haffey, W. G. (1996). School-based prevention for children at risk: the primary mental health project. Washington: American Psychological Association.

Durlak, J. A. \& Wells, A. M. (1997). Primary prevention mental health programs for children and adolescents: a meta-analytic review. American Journal of Community Psychology, 25(2), 115-152.

Fox, D. \& Prilleltensky, I. (Orgs.). (1997). Critical psychology: An introduction. London: Sage.

Freire, P. (1973). Uma educação para a liberdade. Porto: Textos Marginais.

Goldston, S. E. (1980). Defining primary prevention. Em G. W. Albee \& J. M. Joffe (Orgs.), The issues: an overview of primary prevention (pp. 18-23). Hanover: University Press.

Goldston, S. E. (1980). Reaction. Em G. W. Albee, J. M. Joffe \& L. A. Dusenbury (Orgs.), Prevention, powerlessness and politics (pp. 521-524). Newbury Park: Sage Publications.

González Rey, F. (1997). Epistemología cualitativa y subjetividad. São Paulo: EDUC.

Guzzo, R. S. L. (2001). Saúde psicológica, sucesso escolar e eficácia da escola: desafios do novo milênio para a psicologia escolar. Em Z. A. P. Del Prette (Org.), Psicologia escolar e educacional, saúde e qualidade de vida: explorando fronteiras (pp. 25-43). Campinas: Alínea.

Guzzo, R. S. L. (2002). Novo paradigma para a formação e atuação do psicólogo escolar no cenário educacional brasileiro. Em R. S. L. Guzzo (Org.), Psicologia escolar: LDB e educação hoje ( $2^{\mathrm{a}}$ ed) (pp. 131-144). Campinas: Alínea.

Guzzo, R. S. L. (2003). Educação para a liberdade, psicologia da libertação e psicologia escolar: Uma práxis para a liberdade. Em S. F. C. de Almeida (Org.), Psicologia escolar: ética e competências na formação e atuação profissional (pp. 169178). Campinas: Alínea.

Hilliard, T. O. (1981). Political and social action in the prevention of psychopathology of blacks: a mental health strategy for oppressed people. Em J. M. Joffe \& G. W. Albee (Orgs.), Prevention through political action and social change (pp. 135152). Hanover: University Press of New England.

Heller, K. (1996). Coming of age of prevention science: comments on the 1994 National Institute of Mental Health - Institute of Medicine Prevention reports. American Psychologist, 51(11), 1123-1127.

Heffernan, J. \& Albee, G. W. (1985). Prevention perspectives: from Vermont to Washington. American Psychologist, 40(2), 202-204.

Kessler, M. \& Albee, G. W. (1980). An overview of the literature of primary prevention. Em G. W. Albee \& J. M. Joffe (Orgs.), The issues: an overview of primary prevention (pp. 351-399). Hanover: University Press of New England.

Konopka, G. (1981). Social change, social action as prevention: the role of the professional. Em J. M. Joffe \& G. W. Albee (Orgs.), Prevention through political action and social change (pp. 228-239). Hanover: University Press of New England.

Lamb, H. R. (1988). The argument against primary prevention. Em G. W. Albee, J. M. Joffe \& L. A. Dusenbury (Orgs.), Prevention, powerlessness and politics (pp. 516-520). Newbury Park: Sage. 
Lane, S. T. M. (2001). A psicologia social e uma nova concepção do homem para a psicologia. Em S. T. M. Lane \& W. Codo (Orgs.), Psicologia Social: o homem em movimento (13 $\left.{ }^{\mathrm{a}} \mathrm{ed}.\right)$ (pp. 10-19). São Paulo: Brasiliense.

Martín-Baró, I. (2002). Retos y perspectivas de la psicología latinoamericana. Em G. Pacheco \& B. Jiménez (Orgs.), Ignacio Martín-Baró (1942/1989): Psicología de la liberación para América Latina (2 ed.) (pp. 69-89). Guadalajara: ITESO/Universidad de Guadalajara.

Moreira, V. \& Sloan, T. (2002). Personalidade, ideologia e psicopatologia crítica. São Paulo: Escuta.

Muñoz, R. F., Mzarek, P. J. \& Haggerty, R. J. (1996). Institute of Medicine Report on prevention of mental disorders: summary and commentary. American Psychologist, 51(11), 1116-1122.

Patto, M. H. S. (1991). A produção do fracasso escolar. São Paulo: T. A. Queiroz.

Potts, R. G. (2003). Emancipatory education versus school-based prevention in african american communities. American Journal of Community Psychology, 31(1/2), 173-183.

Prilleltensky, I. (1994). The morals and politics of psychology: Psychological discourse and the status quo. Albany: Suny Press.

Prilleltensky, I., Peirson, L. \& Nelson, G. (2001). Mapping the terrain: framework for promoting family wellness and preventing child maltreatment. Em I. Prilleltensky, G. Nelson \&
L. Peirson (Orgs.), Promoting family wellness and preventing child maltreatment: Fundamentals for thinking and action (pp. 3-40). Toronto: University Press of Toronto.

Reiss, D. \& Price, R. H. (1996). National Research Agenda for prevention research: The National Institute of Mental Health Report. American Psychologist, 51(11), 1109-1115.

Sloan, T. (2002). Cultura, cognição e individualismo psicológico. Em V. Moreira \& T. Sloan (Orgs.), Personalidade, ideologia e psicopatologia crítica (pp. 20-35). São Paulo: Escuta.

Trombeta, L. H. A. P. \& Guzzo, R. S. L. (2002). Enfrentando o cotidiano adverso: estudos sobre resiliência em adolescentes. Campinas: Alínea.

Zusman, J. (1988). Reaction. Em G. W. Albee, J. M. Joffe \& L. A. Dusenbury (Orgs.), Prevention, powerlessness and politics (pp. 525-528). Newbury Park: Sage Publications.

Recebido: 05/03/2005 Revisado: 01/12/2005 Aceito: $21 / 12 / 2005$

\section{Nota:}

${ }^{1}$ Esta pesquisa recebeu o apoio do CNPq.

\section{Sobre os autores:}

Fernando Lacerda Júnior: Estudante de graduação em Psicologia da PUC-Campinas.

Raquel Souza Lobo Guzzo: Doutora em Psicologia Escolar e do Desenvolvimento Humano pela Universidade de São Paulo, professora Titular da Faculdade de Psicologia da PUC-Campinas.

Endereço para correspondência: Raquel Souza Lobo Guzzo - Rua Santa Mônica, 136 - Campinas, SP - CEP: 13100-101.

Tel: (19)3729-6867 - Fax: (19)3729-6867 (rguzzo@ mpc.com.br) 